\title{
Studies on the structure of sphingomyelinase
}

\author{
Amino acid composition and heterogeneity on isoelectric focusing
}

\author{
Christopher S. JONES, ${ }^{*} †$ Prema SHANKARAN, ${ }^{*}$ D. Joan DAVIDSON, ${ }^{*}$ Alfred POULOS $\ddagger$ and \\ John W. CALLAHAN* \\ *Research Institute, The Hospital for Sick Children, 555 University Avenue, Toronto, Ontario M5G 1X8, \\ Canada, and $\ddagger$ Department of Chemical Pathology, Adelaide Children’s Hospital, Adelaide, South A ustralia, \\ Australia
}

(Received 28 April 1982/Accepted 28 September 1982)

\begin{abstract}
Sphingomyelinase, purified to apparent homogeneity from human placenta, is an acidic protein, as judged from its amino acid composition and by isoelectric focusing of the carboxymethylated protein. The amino acid composition is characterized by an approximately equal content of hydrophobic and polar amino acid residues. The reduced-alkylated polypeptides were separated into two groups. Most of the polypeptides were heterogeneous with $\mathrm{pI}$ values of 4.4-5.0, but an additional more minor component was observed at pI5.4. Liquid isoelectric focusing resolved the purified enzyme into a single major component (pI 4.7-4.8), a minor component (pI 5.0-5.4) and a plateau region of activity (pI6-7). On thin-layer isoelectric focusing, the protein profile obtained from each of these regions was the same. In addition, the substrate specificity, $K_{\mathrm{m}}$ values and effect of inhibitory substances were identical. We conclude that sphingomyelinase is an acidic, microheterogeneous protein that likely exists as a holopolymer of a single major polypeptide chain. The heterogeneity of the intact protein on isoelectric focusing appears to reflect this microheterogeneity, which is influenced by a tendency to associate with itself and with detergents such as Triton X-100.
\end{abstract}

Few studies have been published on the detailed structure of sphingomyelinase from any source. Recently, Yamanaka \& Suzuki (1982) and ourselves (Jones et al., 1981) reported purification, to apparent homogeneity, of sphingomyelinase from human brain and placenta respectively. The placental enzyme has a major polypeptide chain of about $M_{\mathrm{r}} 89000$ on sodium dodecyl sulphate/polyacrylamide gels and a blocked $N$-terminal amino acid (Jones et al., 1981). The molecular weight of this preparation has not been determined because of the tendency of the enzyme to form aggregates. However, Pentchev et al. (1977) reported an apparent $M_{\mathrm{r}}$ of 290000 for crude placental sphingomyelinase on Sephadex G-200 columns eluted with buffers containing the neutral detergent Cutscum. In the latter study, they isolated a species of placental sphingomyelinase that contained two polypeptides of $M_{\mathrm{r}}$ 36800 and 28300 . The placental enzyme isolated by our procedure also contained small amounts of two

$\uparrow$ Present address: School of Pharmacy, Department of Pharmaceutical Chemistry, University of California, San Francisco, CA 94143, U.S.A. low-molecular-weight polypeptide chains, which we presume are the same as those identified by Pentchev et al. (1977).

The brain enzyme studied by Yamanaka \& Suzuki (1982) has an apparent $M_{\mathrm{r}}$ of 170000 210000 , depending on the detergent concentration. This has also been reported by Gatt \& Gottesdiner (1976). The polypeptide $M_{\mathrm{r}}$ was about 70000 75000 , but the method used was different and not directly comparable with that used by Jones et al. (1981). Similar to our experience, the brain enzyme appeared to have a very high molecular weight in the absence of detergents (Yamanaka \& Suzuki, 1982).

The human enzyme functions as a phospholipase C type of hydrolase, since its substrate specificity includes phosphatidylglycerol (Huterer et al., 1982), and also as a phosphodiesterase, since synthetic phosphodiesters are hydrolysed, in addition to the preferred substrate, sphingomyelin (Jones et al., 1982). However, the human enzyme is clearly distinct from bacterial phospholipase $\mathrm{C}$ and does not share properties of other representative phosphodiesterases that hydrolyse the same phosphodiesters (Brightwell \& Tappel, 1968; Takenawa \& Nagai, 
1981). Therefore, it appears certain that the enzyme is a distinct structural entity.

We report here our recent studies on the amino acid composition, and protein heterogeneity of purified placental sphingomyelinase. The results suggest that the heterogeneity of enzyme activity seen on isoelectric focusing reflects the microheterogeneity of a single major form of the enzyme. The degree of microheterogeneity is influenced by the degree of aggregation that occurs when the enzyme is analysed at low detergent concentrations.

\section{Materials and methods}

\section{Reagents}

Chemicals used in this work were reagent grade or better from a variety of suppliers. Carrier Ampholines were products of LKB Produkter, Bromma, Sweden. Sphingomyelin was bovine brain type 1 from Sigma Chemical Co., St. Louis, MO, U.S.A. $\left[{ }^{3} \mathrm{H}\right]$ Sphingomyelin was purified as described previously (Callahan et al., 1975). Constant-boiling $\mathrm{HCl}$ was purchased from Pierce Chemical Co., Rockville, IL, U.S.A.

\section{Enzyme purification}

Placental sphingomyelinase was purified by the procedure of Jones et al. (1981). The enzyme preparations used in these studies were carried through the final Blue-Sepharose fractionation and were tested for the presence of acid phosphatase. The final specific activity and degree of purification achieved for five separate preparations is shown in Table 1.

\section{Amino acid composition}

The enzyme sample was exhaustively dialysed against water and freeze-dried. The dried residue was then dissolved in water, precipitated with $4 \mathrm{vol}$. of aq. $80 \%$ acetone at $-10^{\circ} \mathrm{C}$ to remove any remaining Triton $\mathrm{X}-100$ and the dried precipitate was finally dissolved in conc. formic acid. The sample was divided into three portions into special evacuation tubes (Pierce Chemical Co.) and the formic acid was evaporated with an $\mathrm{N}_{2}$ stream. To the residue, $0.5 \mathrm{ml}$ of constant-boiling $\mathrm{HCl}$ was added and the sample was frozen, evacuated to below $27 \mathrm{~Pa}$ and then heated in a block heater at $110^{\circ} \mathrm{C}$ for 24, 48 and $72 \mathrm{~h}$. Samples were removed from the heater and dried over $\mathrm{NaOH}$ in an evacuated desiccator. The dried residue was dissolved and the amino acid composition determined as recommended for the Durrum D-400 amino acid analyser. Norleucine was used as the internal standard. The final composition is the result of an average of five analyses on three different enzyme preparations. The composition from all samples for each time period for each amino acid was averaged to arrive at the final result. Cysteine was assayed as cysteic acid and methionine as the sulphone after performic acid oxidation as described by Weber et al. (1972). Arginine values include ornithine, which was found in low and variable concentrations. The final overall composition was obtained by normalizing the data from all runs to alanine.

\section{Isoelectric focusing}

Liquid column isoelectric focusing of the purified enzyme was carried out as described previously (Callahan et al., 1975). Purified enzyme (preparation no. $30 ; 465 \mu \mathrm{g}$ of protein) was electrofocused in a pH3-8 gradient. The column volume was about $110 \mathrm{ml}$ and the final Triton X-100 concentration (calculated from the detergent in the enzyme sample) was $0.03 \%$ and was assumed to be uniformly distributed throughout the gradient. At the end of the experiment, enzyme activity was measured. Enzyme was pooled into three separate fractions, concentrated in an Amicon cell (PM 30 membrane) and exhaustively dialysed against water (7 days; seven changes of 5 litres of water). Enzyme was freeze-dried, dissolved in water and re-focused in a thin-layer electrofocusing system according to the manufacturer's instruction (LKB application 250). Proteins were fixed with $10 \%$ glutaraldehyde and detected with the silver stain by the method of Oakley et al. (1980).

A separate preparation of enzyme $(300 \mu \mathrm{g})$ was reduced and alkylated (Jones et al., 1981) and the denatured protein was separated into its components by isoelectric focusing (pI gradient 3-10) in $8 \mathrm{M}$-urea/1\% Nonidet P40 as described by Mahuran

Table 1. Preparation of placental sphingomyelinase used in the present study

$\begin{array}{cccl}\text { Preparation no. } & \begin{array}{c}\text { Specific activity } \\ \text { (nmol/h per mg) }\end{array} & \begin{array}{c}\text { Purification } \\ \text { (fold) }\end{array} & \begin{array}{c}\text { Usage } \\ 16\end{array} \\ 196000 & 14440 & \text { Amino acid composition } \\ 20 & 124000 & 10000 & \text { Amino acid composition } \\ 24 & 119400 & 10000 & \text { Amino acid composition } \\ 18 & 214000 & 16000 & \text { Isoelectric focusing } \\ 30 & 190000 & 12200 & \text { Isoelectric focusing } \\ \text { Mean } \pm \text { S.D. } & 168680 \pm 19595 & 12520 \pm 1193 & \end{array}$


et al. (1982). The proteins were fixed with trichloroacetic acid and stained with Coomassie Blue. The $\mathrm{pH}$ was determined by cutting a strip of the gel next to the test sample into $0.5 \mathrm{~cm}$ sections and suspending it in water. The $\mathrm{pH}$ was measured after $\mathrm{lh}$ at room temperature.

\section{Enzyme assays}

Sphingomyelinase was determined with $\left[{ }^{3} \mathrm{H}\right]-$ sphingomyelin as described previously (Callahan et al., 1975). Hydrolysis of bis-(4-methylumbelliferyl) phosphate was measured by the method of Jones $e t$ al. (1982). Activity with liposomal sphingomyelin was determined as described by Poulos et al. (1982). Protein was determined by the method of Lowry et al. (1951) as modified by Mather \& Tamplin (1979).

\section{Results}

\section{Enzyme purity}

Several preparations of placental sphingomyelinase were purified to a high degree (Table 1) as judged by polyacrylamide electrophoresis (Fig. 1), sodium dodecyl sulphate/polyacrylamide-gel electrophoresis and by analysis of contaminating enzymes. Acid phosphatase was previously found to be the

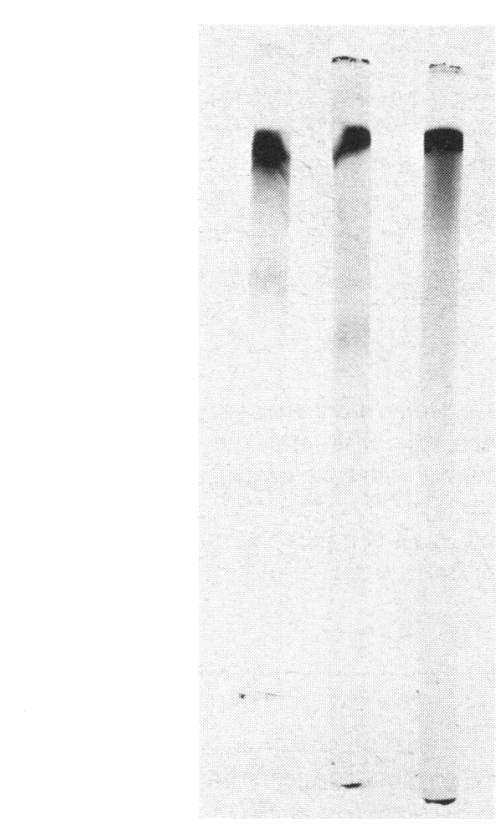

Fig. 1. Polyacrylamide-gel electrophoresis of purified native sphingomyelinase

The $7.5 \%$ gels were run at $\mathrm{pH} 8.3$ in Tris/glycine buffer and stained with Coomassie Blue. Samples $(30-40 \mu \mathrm{g})$ were from preparation nos. 16,18 and 20 (left to right; see Table 1). only significant contaminant and this was reduced to a very low level in all the preparations used in this work (ratio of sphingomyelinase/acid phosphatase was in excess of 30:1 compared with 1:350 in the starting material).

\section{Amino acid composition}

The amino acid composition of the enzyme is shown in Table 2. The composition is normalized to alanine. There are significant amounts of hydrophobic and aromatic amino acid residues. Acidic amino acids generally outnumber basic ones and the polarity index was $\mathbf{4 8 . 1 \%}$ (Capaldi \& Vanderkooi, 1972). Glutamine and asparagine content of the enzyme was estimated after digestion with trypsin alone or with thermolysin. However, the yield of free proline residues was low, indicating that complete digestion was not achieved. The preliminary data show that glutamine and asparagine represent about $35 \%$ and $19 \%$ of the total glutamate and aspartate pools respectively. The apparent partial specific volume of the enzyme based on the amino acid composition is $0.732 \mathrm{~cm}^{3} / \mathrm{g}$ if the aspartate and glutamate are taken as the free acids.

\section{Protein heterogeneity}

The purified acid phosphatase-free enzyme was carboxymethylated as described above and subjected to isoelectric focusing in $8 \mathrm{M}$-urea/1\% Nonidet P40. The polypeptides were very heterogeneous, the majority displaying acidic $\mathrm{pI}$ values from 4.4 to 5.0 (Fig. 2). Additional more acidic components could also be seen (pI values below 4.4). Although in this area (pI 4.4-5.0) there was an apparent continuum

Table 2. Amino acid composition of sphingomyelinase Results are means \pm S.D. All data were normalized to alanine and as a result it does not have an error limit estimates. Abbreviations: N.D., not determined; Cya, cysteic acid.

$\begin{array}{lclc}\begin{array}{c}\text { Amino } \\ \text { acid }\end{array} & \begin{array}{c}\text { Content } \\ \text { (residues/mol) }\end{array} & \begin{array}{c}\text { Amino } \\ \text { acid }\end{array} & \begin{array}{c}\text { Content } \\ \text { (residues/mol) }\end{array} \\ \text { Cya* } & 2.7 \pm 0.6 & \text { Met* } & 1.7 \\ \text { Asp } & 11.4 \pm 0.3 & \text { Ile } \dagger & 4.0 \pm 0.3 \\ \text { Thr } & 4.9 \pm 0.4 & \text { Leu } & 9.1 \pm 0.5 \\ \text { Ser } & 8.5 \pm 0.4 & \text { Tyr } & 1.9 \pm 0.1 \\ \text { Glu } & 11.5 \pm 0.5 & \text { Phe } & 4.0 \pm 0.3 \\ \text { Pro } & 5.5 \pm 0.2 & \text { His } & 2.6 \pm 0.3 \\ \text { Gly } & 9.4 \pm 0.1 & \text { Lys } & 5.8 \pm 0.6 \\ \text { Ala } & 7.7 & \text { Arg } & 3.4 \pm 0.1 \\ \text { Val } \dagger & 6.0 \pm 0.4 & \text { Trp } & \text { N.D. }\end{array}$

* Obtained from performic acid oxidation of a single enzyme preparation. Since methionine is unstable, only the highest value is given.

+ These values are averages of the $72 \mathrm{~h}$ values from the three runs. 


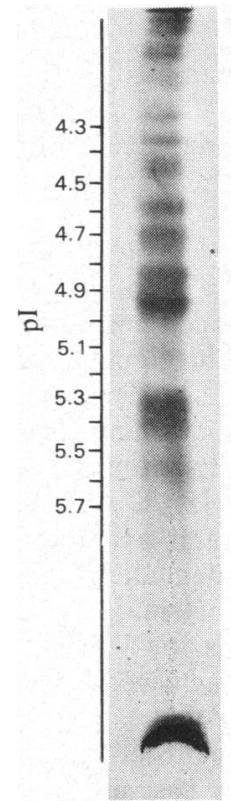

Fig. 2. Thin-layer isoelectric focusing of sphingomyelinase

Enzyme preparation no. 18 was used in this experiment. Note the acidic nature with intense staining at pI 4.6-5.0 and near pI 5.4.

of heterogeneous species, a separate and distinct band with a pI near 5.4 was also found. This region did not stain as intensely as the other areas and may represent the low-molecular-weight polypeptides previously seen (Jones et al., 1981).

Since the protein heterogeneity was consistent with our previous results on heterogeneity of the enzyme activity, it was of interest to examine the nature of the enzyme to determine whether the protein pattern was the same at all isoelectric points. To do this a separate preparation of highly purified enzyme was electrofocused on a liquid column (Fig. 3). The enzyme was resolved into a single major peak with a pI value of 3.7-4.8. On the basic side of this peak a plateau region was discerned at pI 5.2 and a minor more-basic area was noted at pI 6-7. The pattern obtained was essentially the same when enzyme activity was detected with $\left[{ }^{3} \mathrm{H}\right]$ sphingomyelin in the usual way, with bis-(4-methylumbelliferyl) phosphate and with sphingomyelin liposomes. Fractions from each pool were selected and found to hydrolyse phosphatidylglycerol (results not shown). Pooled fractions were then dialysed, concentrated and refocused on horizontal thin-layer acrylamide gels (Fig. 4). It can be seen that the protein pattern is virtually identical for each enzyme pool.

The proteins in these pools were then reduced, alkylated and run in the urea/Nonidet P40-electrofocusing system. However, we were not able to

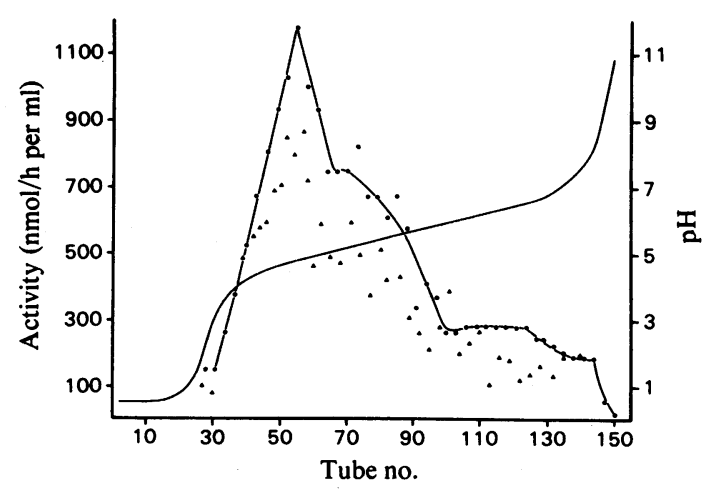

Fig. 3. Column isoelectric focusing of purified sphingomyelinase

The enzyme was exposed to current and the column was eluted as described in the text. Fractions (about $1 \mathrm{ml}$ ) were assayed for activity with sphingomyelin $(\Delta)$ and bis-(4-methylumbelliferyl) phosphate (O). The continuous line represents the $\mathrm{pH}$ gradient. Fractions were pooled (pool 1, tubes 35-50; pool 2, tubes 75-90; pool 3, tubes 110-130) and processed as described in the text.

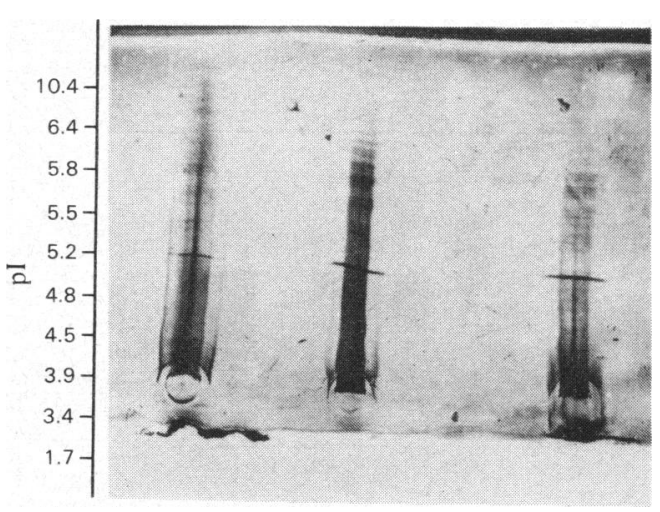

Fig. 4. Thin-layer electrofocusing of pooled enzyme The $\mathrm{pH}$ gradient was 3-8 and the $\mathrm{pH}$ measurements were made in water as described in the text. The samples were (left to right) pool 1 , pool 2 and pool 3. Note that in all samples the major band had the same pI and that the degree of heterogeneity was the same.

obtain a satisfactory photographic representation of the results owing to substances interfering with the silver stain. The pattern for each of the three pools was the same and was consistent with the pattern shown in Fig. 2.

\section{Kinetic properties}

The three pools of enzyme were assayed to determine their properties. The $K_{\mathrm{m}}$ value for the two 
Table 3. Properties of isoelectric focusing pools

The substrate used to obtain these estimates was sphingomyelin. Both bis-(4-methylumbelliferyl) phosphate and phosphatidylglycerol are also substrates.

\begin{tabular}{|c|c|c|c|c|c|}
\hline \multirow[b]{3}{*}{ Fraction } & \multirow[b]{3}{*}{ pI } & \multirow[b]{3}{*}{$K_{\mathrm{m}}$} & \multicolumn{3}{|c|}{ Inhibition (\%): } \\
\hline & & & \multicolumn{2}{|c|}{ By AMP } & \multirow{2}{*}{$\begin{array}{c}\text { By } 80 \mu \mathrm{g} \text { of } \\
\text { phosphatidylglycerol }\end{array}$} \\
\hline & & & $0.2 \mathrm{~mm}$ & $0.4 \mathrm{~mm}$ & \\
\hline $\begin{array}{l}\text { Pool } 1 \\
\text { Pool } 2\end{array}$ & $\begin{array}{l}4.80 \\
5.20\end{array}$ & $\begin{array}{l}8.6 \\
9.8\end{array}$ & $\begin{array}{l}45 \\
41\end{array}$ & $\begin{array}{l}58 \\
61\end{array}$ & $\begin{array}{l}36 \\
30\end{array}$ \\
\hline
\end{tabular}

major pools of enzyme was $8.6 \mu \mathrm{M}$ and $9.8 \mu \mathrm{M}$ at pH4.6 and with constant-ionic-strength buffers respectively (Table 3 ). Each pool was inhibited by AMP and phosphatidylglycerol and each was unaffected by $0.1 \mathrm{~mm}$-mercuribenzoate. We conclude that the properties of each enzyme pool are the same.

\section{Discussion}

The enzyme preparations used in this study were isolated over the course of 18 months and represent pools of enzyme obtained from approx. 40 placentae in total. The degree of purification (12500-fold) and specific activity $(168000 \mathrm{nmol} / \mathrm{h}$ per $\mathrm{mg})$ is comparable with our previous preparations as judged by polyacrylamide-gel electrophoresis and the low level of contaminants. We previously showed that the final step in the purification, chromatography on Blue-Sepharose, separates active from denatured enzyme, since the major proteins detected on sodium dodecyl sulphate gels are substantially the same. This is reflected in the final specific activity achieved in two of the five preparations included in this study, where the specific activity is lower than for the other preparations and they are presumed to contain somewhat more denatured enzyme than the others. All the preparations were monitored for hydrolysis of bis-(4-methylumbelliferyl) phosphate and for acid phosphatase contamination. The amino acid composition obtained represents the average values from three preparations and must be considered representative since it includes a degree of individual variation. The standard error quoted for each amino acid reflects the relative stability of the residue under the experimental conditions but overall the data indicate that good reproducibility between preparations has been achieved. The composition is not particularly noteworthy in comparison with the analyses for other lysosomal hydrolases such as $\beta$-hexosaminidase (Geiger \& Arnon, 1976), $\beta$ galactosidase (Norden et al., 1974) or $\beta$-glucuronidase (Lusis \& Paigen, 1978). A polarity index for sphingomyelinase has been calculated according to the recommendations of Capaldi \& Vanderkooi (1972). The value obtained $(48.1 \%)$ is in the range expected for soluble proteins (41-53\%) and is distinct from that found for intrinsic membrane proteins (less than 40\%). Thus, the hydrophobic character of this enzyme derives from its amino acid sequence rather than from a high content of hydrophobic residues.

Sphingomyelinase is clearly heterogeneous as shown in the present work. This is true for the highly purified active enzyme and a carboxymethylated polypeptide preparation. The purified enzyme was examined in the liquid column system at an initial concentration of about $4 \mu \mathrm{g}$ of protein $/ \mathrm{ml}$ of electrofocusing fluid. The pattern obtained, shown in Fig. 3 , is reminiscent of the pattern found in crude liver and brain extracts. In these early experiments the enzyme was resolved into two major fractions with acidic pI values of 4.6 and 4.8 (Callahan et al., 1975). The pattern obtained with the purified enzyme clearly indicates that heterogeneity is an intrinsic property of the enzyme and not simply due to association with other contaminating proteins, a possible interpretation of the early data. Indeed, the crude placental enzyme is essentially equivalent to the purified enzyme in this regard and the results show that a protein preparation representative of the total tissue pool has been obtained. This judgment is also based on the high yield of the present procedure. It is also clear that Triton X-100 cannot be responsible for the heterogeneity of the native purified enzyme since similar data have been obtained in the absence of exogenously added detergents (Callahan et al., 1980).

The microheterogeneity of the intact protein as judged by the enzyme activity and the protein staining is comparable with that found for other acid hydrolases such as $\beta$-hexosaminidase and $\beta$-glucuronidase. It was found (Mahuran \& Lowden, 1981; Mahuran et al., 1982) that human placental $\beta$-hexosaminidase $B$ could be separated into several bands of enzyme activity on thin-layer electrofocusing gels even though the denatured protein appeared pure by conventional sodium dodecyl sulphate/polyacrylamide-gel electrophoresis. Similarly purified mouse liver and urine $\beta$-glucuronidase displayed microheterogeneity of enzyme activity. In the latter study, Lusis \& Paigen (1978) demonstrated that this 
was not due to differences in the carbohydrate composition or degree of phosphorylation of the enzyme. More recent studies by Mahuran et al. (1982) indicate this is also true for $\beta$-hexosaminidase B. Furthermore, Lusis \& Paigen (1978) obtained a similar degree of microheterogeneity for the enzyme, which had slightly different $\mathrm{pI}$ values from different inbred strains of mice. The current view is that both $\beta$-hexosaminidase $B$ and $\beta$ glucuronidase contain products of a single gene. In the case of sphingomyelinase the microheterogeneity observed cannot be due to protein aggregation of the native enzyme since the heterogeneity was as marked for the denatured carboxymethylated protein in the presence of urea and Nonidet P40 as for the native enzymes. It also appears certain, from the experience of Lusis \& Paigen (1978) and our data on analysis of single tissue specimens that the heterogeneity cannot be ascribed simply to pooling of several tissues. The reason for the microheterogeneity is not defined in our studies although it seems certain that deamidation reactions are in part responsible. This is clear from the detection of ornithine in various amounts in the amino acid analyses. However, we cannot ascribe this with certainty to other residues, such as glutamine and asparagine, without additional studies. Ornithine is presumed to derive from post-translational processing of the intact protein. The purification of sphingomyelinase did not employ buffers with alkaline $\mathrm{pH}$ values or employ conditions which have been known to artifactually produce this amino acid. Evidence for the occurrence of ornithine in proteins was recently summarized by Akers \& Dromgoole (1982).

The urea-focusing experiments on the purified and carboxymethylated enzyme show that two groups of polypeptides can be resolved. The one major group is very microheterogeneous and displays $\mathrm{pI}$ values of 5.0-4.0 and lower. The second group has a pI value of about 5.4. The staining intensity suggests it represents one or more minor components that have pI values distinct from and more basic than the major components. It is possible that these components represent the two minor polypeptides previously observed (Pentchev et al., 1977; Jones et al., 1981) but this is not certain as yet. The present data indicate that sphingomyelinase is likely composed of a single major polypeptide chain.

More than a single major form of sphingomyelinase probably does not exist, at least in the placenta. This is suggested by the failure to identify different major groups of polypeptides corresponding to the species separated by column electrofocusing. It is also likely that sphingomyelinase proteins, because of their relatively high molecular-weight values, are not subjected to extensive endopeptidase cleavage. In this regard, the protein would be more like $\alpha$-glucosidase monomers (Neufeld, 1981) than $\beta$-hexosaminidase. The latter appears to be cleaved near the middle and both cleavage products, which are found in the final protein, can be easily resolved in the urea-focusing system. The finding of microheterogeneity in the sphingomyelinase protein is not unusual, since the same observations have been made for several other proteins purified to a high degree. These include aldolase and pyruvate kinase (Susor et al., 1973) and fumarase (Cohen et al., 1973) in addition to the hydrolases mentioned above.

Estimates of the molecular weight of sphingomyelinase have ranged from 170000 to 300000 , depending on enzyme source and experimental conditions ( $\mathrm{pH}$ value, detergents). In our hands, the placental enzyme gave a molecular weight value greater than $2 \times 10^{6}$ on a high-pressure-liquidchromatograph column (P. Strasberg, unpublished work). This is not considered an accurate value since the enzyme aggregates under the experimental conditions employed (absence of detergents). It thus appears that, at least for now, the estimates must be made with buffers containing detergents. Yamanaka \& Suzuki (1982) recently obtained values of 170000-210000, depending on detergent concentration for the human brain enzyme, and on the basis of a polypeptide molecular-weight estimate of 89000 the minimum form of the fully active enzyme would be a dimer.

The structure of sphingomyelinase (dimer, tetramer) and the number of isoenzyme forms in tissues is of importance to our understanding of the juvenile form of Niemann-Pick disease (type C). Our data (Callahan et al., 1975) and those of others (Besley, 1977; Minami et al., 1979) have suggested an abnormally low content of some components of the enzyme on the basis of isoelectric focusing experiments. These results have been interpreted as a deficiency in specific isoenzymic forms of the enzyme. The present data do not clarify this issue, since by analogy with fumarase the heterogeneous polypeptides could randomly associate to form a large number of active enzymes, which would display multiple isoelectric points. It appears certain that the resolution of this question requires purification and characterization of the enzyme in tissues derived from well-defined cases of this disease.

We are indebted to Dr. J. A. Lowden, Dr. D. Mahuran and Dr. P. Strasberg for helpful discussion and criticism. This work was made possible through a grant from the Medical Research Council of Canada (PG-4).

\section{References}

Akers, H. A. \& Dromgoole, E. V. (1982) Trends Biochem. Sci. 7, 156-157 
Besley, G. T. N. (1977) FEBS Lett. 80, 71-74

Brightwell, R. \& Tappel, A. L. (1968) Arch. Biochem. Biophys. 124, 325-332

Callahan, J. W., Khalil, M. \& Philippart, M. (1975) Pediatr. Res. 9, 908-913

Callahan, J. W., Gerrie, J., Jones, C. S. \& Shankaran, P. (1980) Biochem. J. 193, 275-283

Capaldi, R. A. \& Vanderkooi, G. (1972) Proc. Natl. Acad. Sci. U.S.A. 69, 930-932

Cohen, L. H., Penner, P. E. \& Loeb, L. A. (1973) Ann. N.Y. Acad. Sci. 209, 354-362

Gatt, S. \& Gottesdiner, T. (1976) J. Neurochem. 26, 421-422

Geiger, B. \& Arnon, R. (1976) Biochemistry 15, 3484-3493

Huterer, S., Wherrett, J. R., Poulos, A. \& Callahan, J. W. (1982) Neurology in the press

Jones, C. S., Shankaran, P. \& Callahan, J. W. (1981) Biochem. J. 195, 373-382

Jones, C. S., Davidson, D. J. \& Callahan, J. W. (1982) Biochim. Biophys. Acta 701, 261-268

Lowry, O. H., Rosebrough, N. J., Farr, A. L. \& Randall, R. J. (1951) J. Biol. Chem. 193, 265-275

Lusis, A. J. \& Paigen, K. (1978) J. Biol. Chem. 253, 7336-7345

Mahuran, D. \& Lowden, J. A. (1981) Can. J. Biochem. 59, 237-241
Mahuran, D., Tsui, F., Gravel, R. A. \& Lowden, J. A. (1982) Proc. Natl. Acad. Sci. U.S.A. 79, 1602-1605

Mather, I. H. \& Tamplin, C. B. (1979) Anal. Biochem. 93, 139-142

Minami, R., Matsuura, Y., Nakamura, F., Kudoh, T., Sogawa, H., Oyamagi, K., Sukegawa, K., Orii, T., Maruyama, K. \& Nakao, T. (1979) Hum. Genet. 47, 159-167

Neufeld, E. F. (1981) in Lysosomes and Lysosomal Storage Diseases (Callahan, J. W. \& Lowden, J. A., eds.), pp. 115-129, Raven Press, New York

Norden, A. G. W., Tennant, L. L. \& O'Brien, J. S. (1974) J. Biol. Chem. 249, 7969-7976

Oakley, B. R., Kirsch, D. R. \& Morris, N. R. (1980) Anal. Biochem. 105, 361-363

Pentchev, P. G., Brady, R. O., Gal, A. E. \& Hibbert, S. R. (1977) Biochim. Biophys. Acta 488, 312-321

Poulos, A., Jones, C. S., Shankaran, P. \& Callahan, J. W. (1982) Trans. Am. Soc. Neurochem. 13, 58

Susor, W. A., Kochman, M. \& Rutter, W. J. (1973) Ann. N.Y. Acad. Sci. 209, 328-344

Takenawa, T. \& Nagai, Y. (1981) J. Biol. Chem. 256, 6769-6775

Weber, K., Pringle, J. R. \& Osborn, M. (1972) Methods Enzymol. 26, 3-27

Yamanaka, T. \& Suzuki, K. (1982) J. Neurochem. 38, 1753-1764 